\title{
Light-emitting filaments composed of nanometer-sized carbon hollow capsules
}

\author{
Koji Asaka ${ }^{a)}$ \\ Special Research Project on Nanoscience, Graduate School of Pure and Applied Sciences, \\ University of Tsukuba, Tsukuba 305-8571, Japan \\ Ryoei Kato \\ Institute of Materials Science, Graduate School of Pure and Applied Sciences, University of Tsukuba, \\ Tsukuba 305-8573, Japan \\ Yoshinari Maezono \\ PREST, JST, Tsukuba 305-8573, Japan \\ Ryozo Yoshizaki \\ Institute of Materials Science, and Special Research Project on Nanoscience, Graduate School of Pure and \\ Applied Sciences, University of Tsukuba, Tsukuba 305-8573, Japan \\ Kun'ichi Miyazawa \\ Ecomaterials Center, National Institute for Materials Science, 1-1, Namiki, Tsukuba 305-0044, Japan \\ Tokushi Kizuka \\ Institute of Materials Science, and Special Research Project on Nanoscience, Graduate School of Pure and \\ Applied Sciences, University of Tsukuba, Tsukuba 305-8573, Japan, and PREST, JST, Tsukuba \\ 305-8573, Japan
}

(Received 6 July 2005; accepted 16 December 2005; published online 2 February 2006)

\begin{abstract}
Filaments composed of multilayered carbon hollow capsules less than $10 \mathrm{~nm}$ in diameter have been synthesized from crystalline whiskers of fullerene $\mathrm{C}_{60}$ of submicrometer in diameter by preliminary heating at $1373 \mathrm{~K}$ and successive impression of current. The structural, electrical and optical properties of the filaments were studied by in situ transmission electron microscopy combined with the functions of scanning probe microscopy. We found that the filaments easily emit visible light at a maximum wavelength of $700-730 \mathrm{~nm}$ by the application of a few volts. (C) 2006 American Institute of Physics. [DOI: 10.1063/1.2172013]
\end{abstract}

Fullerene $\mathrm{C}_{60}$ molecules ${ }^{1}$ crystallize in films and plates. $^{2-5}$ Superconductivity, ${ }^{6}$ electrical conductivity, ${ }^{7,8}$ hardness ${ }^{9}$ and deformation ${ }^{10}$ of the single crystalline $\mathrm{C}_{60}$ films and plates have been studied. Recently, the synthesis method of single crystalline whiskers of $\mathrm{C}_{60}$ with a face centered cubic structure of submicrometer in diameter and more than $100 \mu \mathrm{m}$ in length was discovered by Miyazawa et $a l .{ }^{11,12}$ The electrical resistivity of the $\mathrm{C}_{60}$ whiskers is in the range from $10^{6}$ to $10^{8} \Omega \mathrm{m}$ and the same order as that of other $\mathrm{C}_{60}$ crystals with film and plate shapes. ${ }^{13}$ By heating at $1373 \mathrm{~K}$ in a vacuum, the resistivity becomes much smaller than that of the pristine $\mathrm{C}_{60}$ whiskers. In this paper, we report a fabrication of light-emitting carbon filaments using the heated whiskers by applying voltage. The structure and the relation between the electrical and optical properties are investigated.

The crystalline $\mathrm{C}_{60}$ whiskers were synthesized by a liquid-liquid interfacial precipitation method. ${ }^{11-13}$ The $\mathrm{C}_{60}$ whiskers were heated in a high vacuum at $1373 \mathrm{~K}$ for $30 \mathrm{~min}$. The atomistic structural dynamics and electrical, optical properties of the heated whiskers were simultaneously analyzed by in situ transmission electron microscopy combined with the functions of scanning probe microscopy. ${ }^{14}$ The heated whiskers were fixed on a tip of a silver electrode of $50 \mu \mathrm{m}$ thickness with a rectangular shape. Then the electrode was mounted on a specimen holder for the microscope.

\footnotetext{
${ }^{a)}$ Electronic mail: asaka@sakura.cc.tsukuba.ac.jp
}

The silicon cantilever coated with a thin silver film, as used for atomic force microscopy, was fixed in front of a tubetype piezo on another holder. The cantilever was manipulated by a piezo-driven system and brought into contact with one of the whiskers. Then, bias voltage was applied between the cantilever and the electrode at room temperature in a vacuum of $1 \times 10^{-5} \mathrm{~Pa}$. The electrical conductance was measured by a two-terminal method. The atomistic structural variation was simultaneously observed by in situ highresolution transmission electron microscopy using a TV rate system. The high-resolution images were recorded on videotapes at a time resolution of $17 \mathrm{~ms}$. The light emission inside the microscope were also measured using a CCD camera.

Figures 1(a) and 1(b) show a low-magnification image and an electron diffraction pattern of a heated whisker, respectively. The regions in the right-hand and left-hand sides of Fig. 1(a) are a tip of the cantilever (A) and that of the electrode (B), respectively. The diameter and length of the whisker lying between the tip and the electrode are $1.1 \mu \mathrm{m}$ and more than $8.3 \mu \mathrm{m}$, respectively. The electron diffraction pattern in Fig. 1(b) is a hallow pattern, indicating that the structure of the heated whisker is amorphous one. Next, bias voltage was applied to both tips of the whisker in Fig. 1(a). The current-voltage curve observed is shown in Fig. 2. The current increases gradually from bias voltage of $0-3.5 \mathrm{~V}$. At $4.0 \mathrm{~V}$, the current abruptly increases to $0.89 \mathrm{~mA}$, and then abruptly decreases to zero at $4.5 \mathrm{~V}$. The electrical resistivity reduces from $9.8 \times 10^{-4} \Omega \mathrm{m}$ to $4.4 \times 10^{-4} \Omega \mathrm{m}$. These val- 

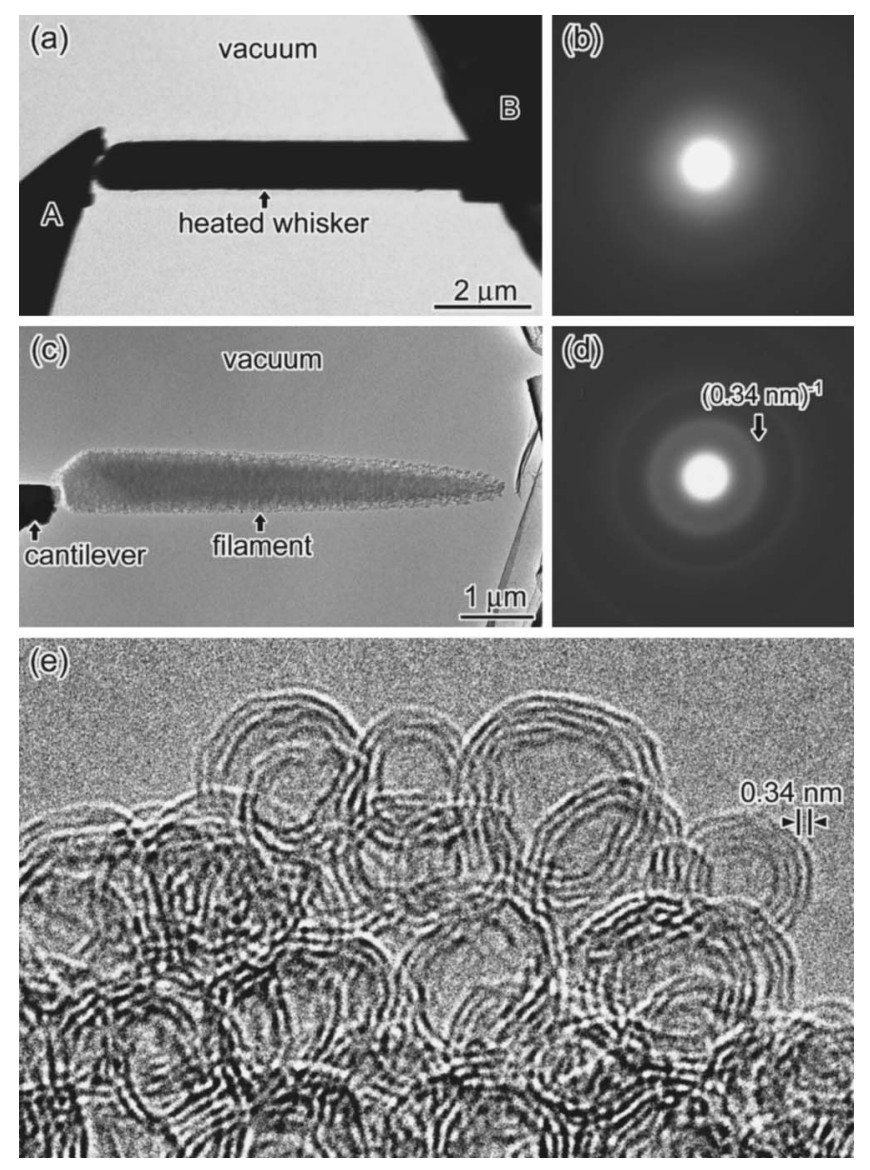

FIG. 1. (a) Low-magnification image and (b) electron diffraction pattern of a whisker prepared by heating of a $\mathrm{C}_{60}$ whisker. (c) Low-magnification image and (d) electron diffraction pattern of the whisker after structural change due to the impressive current. (e) High-resolution image of the surface of the whisker in (c). The whisker is composed of multilayered carbon hollow capsules of less than ten nanometers in diameter. The whisker in (c) is the filament emitting visible light.

ues are much smaller than that of the pristine crystalline $\mathrm{C}_{60}$ whiskers. ${ }^{13}$ After $4.5 \mathrm{~V}$ was applied in the whisker, a lowmagnification image and an electron diffraction pattern were taken as shown in Figs. 1(c) and 1(d), respectively. The whisker gradually becomes narrow toward the right-hand side and the contact with the electrode completely fractures. Debye rings in Fig. 1(d) are broad. The width of the smallest Debye ring corresponds to around $(0.34 \mathrm{~nm})^{-1}$ and is close to that of the 00.2 reflections from graphite. Figure $1(\mathrm{e})$ is a high-resolution image of the surface of the whisker in Fig.

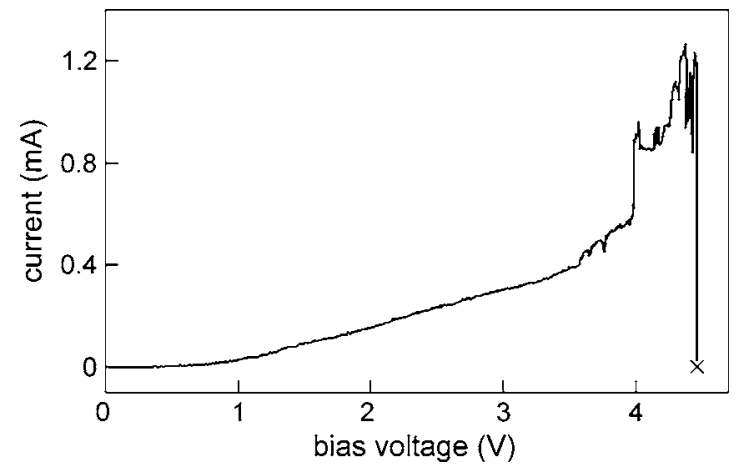

FIG. 2. Current-voltage curve of the whisker in Fig. 1(c). The abrupt increase of current at the bias voltage of $4 \mathrm{~V}$ indicates that the structural

change occurs. Cross indicates the fracture of the contact. naked eyes at a distance of 250 mm. The maximum peak
Downloaded 09 Nov 2009 to 130.158.56.186. Redistribution subject to AlP license or copyright; see http://apl.aip.org/apl/copyright.jsp

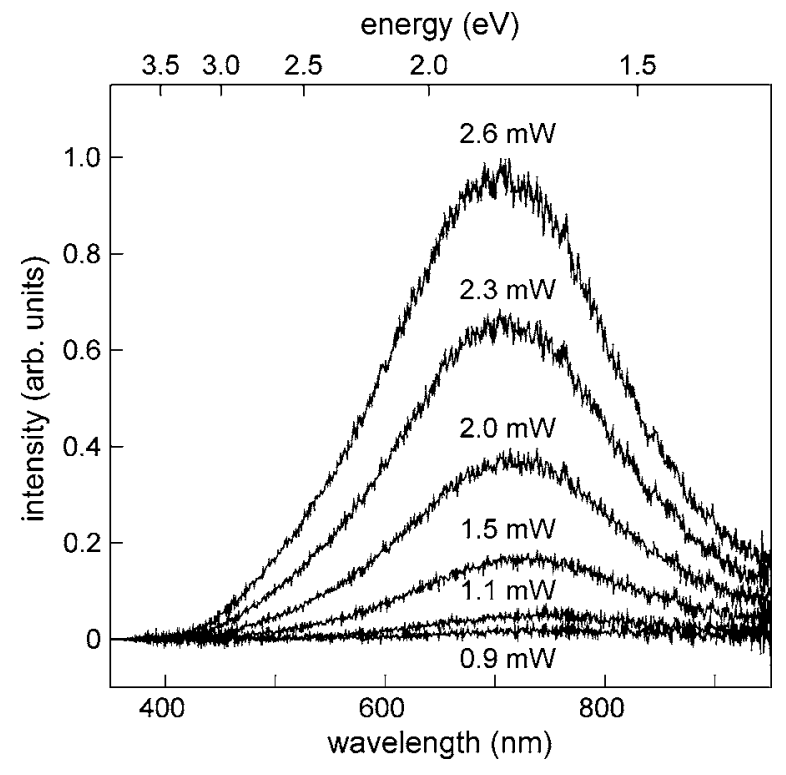

FIG. 3. Emission spectra of a whisker composed of carbon capsules at various electric powers.

1(c). The carbon hollow capsules surrounded with walls of a few atomic layers are synthesized. The capsules are observed on the whole surfaces of the whisker. The spacing of the atomic layers is $0.34 \pm 0.05 \mathrm{~nm}$, corresponding to the interThe outer diameter of the capsules ranges from 3 to $8 \mathrm{~nm}$. It was found from in situ observation that the structural change from the amorphous to the capsules started from $3.5 \mathrm{~V}$. The electrical resistivity also starts to change from same voltage. Thus, the change in resistivity is caused by the structural transformation. It was reported that similar capsulestructures were produced by heating of carbon soot at $2373 \mathrm{~K} .{ }^{15}$ The molecular dynamics simulation regarding the nucleation mechanism of the fullerene $\mathrm{C}_{60}$ also showed that randomly arranged carbon atoms started to form spherical clusters with hexagonal rings at $2000 \mathrm{~K} .{ }^{16}$ In this study, we did not perform any heat treatment. However, resistive Joule heating occurs due to the impressive current inside the microscope. It is deduced that the formation of the capsules results from an increase in temperature due to the resistive Joule heating.

After the formation of the capsules, we contacted the whiskers with the electrode again. The bias voltage was increased from $0 \mathrm{~V}$ and the whiskers started to illuminate. We demonstrate typical emission characteristics using a whisker composed of multilayered carbon hollow capsules as an example. Figure 3 shows the emission spectra of the whisker at various electric powers. Figure 4 shows the emission intensity of the spectra from 350 to $950 \mathrm{~nm}$ in wavelength as a function of electric power. The threshold electric power for the light emission is $0.84 \mathrm{~mW}$, as shown by an arrow in Fig. 4. The emission intensity increases with an increase in the electric power from the threshold. The power applied at the whisker is lower than those required for high-intensity electroluminescence in other organic light-emitting devices, e.g., the aluminium 8-hydroxyquinoline complex. ${ }^{17}$ In Fig. 3, as the electric power increases, the full width at half maximum of the spectra reduces: the width is $\sim 240 \mathrm{~nm}$ at $2.6 \mathrm{~mW}$. At this electric power, the luminescence was easily seen by the naked eyes at a distance of $250 \mathrm{~mm}$. The maximum peak AIP license or copyright; see http://apl.aip.org/apl/copyright.jsp layer spacing of graphite. The number of the layers is 2-4. 


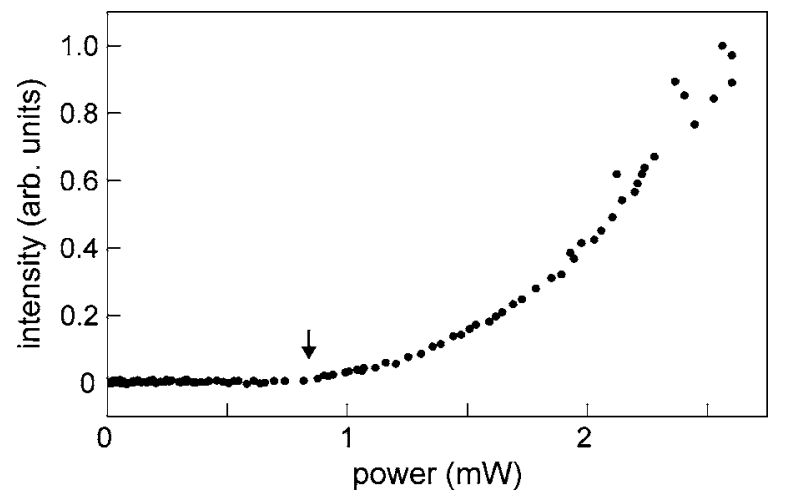

FIG. 4. Emission intensity of a whisker composed of carbon capsules as a function of the electric power.

ranges from 700 to $730 \mathrm{~nm}$, corresponding to $1.70-1.77 \mathrm{eV}$. These spectra are composed of Gaussian components and black-body radiation components. The intensity of blackbody radiation components is a few percents of the total and corresponding temperature is $1000-1100 \mathrm{~K}$ for the spectrum of $2.6 \mathrm{~mW}$. Thus, most of the emission intensity is caused by the electroluminescence. The peaks of the spectra due to electroluminescence from the $\mathrm{C}_{60}$ crystals are 530, 920, or $1700 \mathrm{~nm}$ (Refs. 18-20) and different from the peaks in this study. On the other hand, in the previous reports of the photoluminescence from the $\mathrm{C}_{60}$ crystals, the spectra showed intense emission peaks around $730 \mathrm{~nm}$, and the origins are extensively discussed. ${ }^{21-25}$ According to Matus et al., the peaks were explained based on the recombination of selftrapped excitons on the $\mathrm{C}_{60}$ molecules. ${ }^{23}$ The wavelength of the peaks is similar to that of the whiskers composed of the carbon capsules in this study, though the structures are different. It is suggested that similar atomistic configurations exist in the present carbon capsules and the $\mathrm{C}_{60}$ crystals, and the emission around $730 \mathrm{~nm}$ is caused by similar transitions. However, the details of the atomistic arrangements of the carbon capsules were not analyzed, and then the accurate excitation process and the electronic structure have not been apparent.

The starting materials in this study are the $\mathrm{C}_{60}$ whiskers with the high aspect ratio of length to diameter. After the structural transformation to the carbon capsules by heating, the whisker shape is maintained. Thus, we can easily synthesize the filament shape using the $\mathrm{C}_{60}$ whiskers.

Light-emitting devices of submicrometer or nanometer size can be utilized for various purposes in medical, biologi$\mathrm{cal}$, and material science, for instance, illuminating the interior of blood vessels or optically controlling other devices. The materials of the light-emitting devices should be suitable for biology and environment. The whiskers composed of nanometer-sized carbon hollow capsules in this study can be used as light-emitting filaments for such applications.

This work was partly supported by the funds for the Special Research Project on Nanoscience and the University Research Projects of the University of Tsukuba, and by a Grant-in-Aid for Scientific Research from the Ministry of Education, Science, Sports and Culture of Japan. Additional financial support for the present study was provided by the Nippon Sheet Glass Foundation.

${ }^{1}$ H. W. Kroto, J. R. Heath, S. C. O'Brien, R. F. Curl, and R. E. Smalley, Nature (London) 318, 162 (1985).

${ }^{2}$ W. Krätschmer, L. D. Lamb, K. Fostiropoulos, and D. R. Huffman, Nature (London) 347, 354 (1990).

${ }^{3}$ R. L. Meng, D. Ramirez, X. Jiang, P. C. Chow, C. Diaz, K. Matsuishi, S. C. Moss, P. H. Hor, and C. W. Chu, Appl. Phys. Lett. 59, 3402 (1991).

${ }^{4}$ J. Z. Liu, J. W. Dykes, M. D. Lan, P. Klavins, R. N. Shelton, and M. M. Olmstead, Appl. Phys. Lett. 62, 531 (1993).

${ }^{5}$ M. Haluska, H. Kuzmany, M. Vybornov, P. Rogl, and P. Fejdi, Appl. Phys. A A56, 161 (1993).

${ }^{6}$ K. Kikuchi, S. Suzuki, K. Saito, H. Shiromaru, I. Ikemoto, Y. Achiba, A. A. Zakhidov, A. Ugawa, K. Imaeda, H. Inokuchi, and K. Yakushi, Physica C 185, 415 (1991).

${ }^{7}$ T. Arai, Y. Murakami, H. Suematu, K. Kikuchi, Y. Achiba, and I. Ikemoto, Solid State Commun. 84, 827 (1992).

${ }^{8}$ J. Mort, R. Ziolo, M. Machonkin, D. R. Huffman, and M. I. Ferguson, Chem. Phys. Lett. 186, 284 (1991).

${ }^{9}$ M. Tachibana, M. Michiyama, K. Kikuchi, Y. Achiba, and K. Kojima, Phys. Rev. B 49, 14945 (1994).

${ }^{10}$ Y. A. Ossipyan, V. S. Bobrov, Y. S. Grushko, R. A. Dilanyan, O. V. Zharilov, M. A. Lebyodkin, and V. S. Sheckhtman, Appl. Phys. A 56, 413 (1993).

${ }^{11}$ K. Miyazawa, A. Obayashi, and M. Kuwabara, J. Am. Ceram. Soc. 84, 3037 (2001).

${ }^{12}$ K. Miyazawa, K. Hamamoto, S. Nagata, and T. Suga, J. Mater. Res. 18, 1096 (2003).

${ }^{13}$ K. Miyazawa, Y. Kuwasaki, K. Hamamoto, S. Nagata, A. Obayashi, and M. Kuwabara, Surf. Interface Anal. 35, 117 (2003).

${ }^{14}$ T. Kizuka, H. Ohmi, T. Sumi, K. Kumazawa, S. Deguchi, M. Naruse, S. Fujisawa, S. Sasaki, A. Yabe, and Y. Enomoto, Jpn. J. Appl. Phys., Part 1 40, L170 (2001).

${ }^{15}$ W. A. de Heer and D. Ugarte, Chem. Phys. Lett. 207, 480 (1993).

${ }^{16}$ J. R. Chelikowsky, Phys. Rev. Lett. 67, 2970 (1999).

${ }^{17}$ J. Kalinowski, J. Phys. D 32, R179 (1999).

${ }^{18}$ M. Uchida, Y. Ohmori, and K. Yoshino, Jpn. J. Appl. Phys., Part 1 30, L2104 (1991).

${ }^{19}$ A. T. Werner, J. Anders, H. J. Byrrne, W. K. Maser, M. Kaiser, A. Mittelbach, and S. Roth, Appl. Phys. A 57, 157 (1993).

${ }^{20}$ T. T. M. Palstra, R. C. Haddon, and K. B. Lyons, Carbon 35, 1825 (1997).

${ }^{21}$ C. Reber, L. Yee, J. Mckiernan, J. I. Zink, R. S. Williams, W. M. Tong, D. A. A. Ohlberg, R. L. Whetten, and F. Diederich, J. Phys. Chem. 95, 2127 (1991).

${ }^{22}$ J. Feldmann, R. Fischer, W. Guss, E. O. Göbel, S. Schmitt-Rink, and W. Krätschmer, Europhys. Lett. 20, 553 (1992).

${ }^{23}$ M. Matus, H. Kuzmany, and E. Sohmen, Phys. Rev. Lett. 68, 2822 (1992).

${ }^{24}$ W. Guss, J. Feldmann, E. O. Göbel, C. Taliani, H. Mohn, W. Müller, P. Häussler, and H.-U. ter Meer, Phys. Rev. Lett. 72, 2644 (1994).

${ }^{25}$ Y. Wang, J. M. Holden, A. M. Rao, P. C. Eklund, U. D. Venkateswaran, D. Eastwood, R. L. Lidberg, G. Dresselhaus, and M. S. Dresselhaus, Phys. Rev. B 51, 4547 (1995). 